\title{
Light and Electron Microscopic Observations of Giant Cells in the Mouse Testis after Efferent Duct Ligation*
}

\author{
Shio Kumar SingH ${ }^{1,2}$ and Kazuhiro ABE ${ }^{2}$ \\ Department of Zoology ${ }^{1}$, Banaras Hindu University, Varanasi, India and Department of Anatomy \\ (Prof. K. ABE) ${ }^{2}$, Hokkaido University School of Medicine, Sapporo, Japan
}

Received September 30, 1987

Summary. Multinucleated giant cells in the mouse testis after ligation of the efferent duct were examined by light and electron microscopy. The findings suggest that the giant cells are formed as a result of the fusion of spermatids due to alterations in the intercellular bridges. Further, the orientation of acrosomes, nuclei, and organelles for formation of the tail in the giant cells is related to the polarity of the spermatids.

The occurrence of giant cells in the testes of several mammalian species following various kinds of testicular injuries is well documented (BENITZ and DAMBACH, 1965; Holstein, 1975; Singh, 1982; Holstein and ECKMANN, 1986). The giant cells contain multiple nuclei of germ cells. Electron microscopic studies show that the germ cells in the seminiferous tubules are connected to each other by intercellular bridges (DYM and FAWCETT, 1971). It has also been suggested that the giant cells are formed by the fusion of germ cells, and this fusion occurs due to damage to the intercellular bridges (PLÖEN, 1973a, b; TORGERSEN et al., 1982). However, the exact mechanism of the formation of giant cells remains unknown. In the present study, we observed the cells after efferent duct ligation and found that the fusion of spermatids and their subsequent orientation in the giant cells is related to the polarity of spermatids during spermiogenesis.

\section{MATERIALS AND METHODS}

Twenty-four adult male dd-mice were used in this study. The ligation of the efferent duct was done under pentobarbital sodium (Nembutal) anesthesia injected intraperitoneally. The testis and epididymis were exposed through a median incision of the lower abdomen, and the efferent duct was ligated on both sides under a dissection microscope. Groups of six mice were killed at intervals of 2, 4, 6 and 8 days after surgery, and the testis was examined.

For light microscopy, the testis was fixed in Bouin's fluid for $3 \mathrm{hrs}$, dehydrated, embedded in paraffin, sectioned at $6 \mu \mathrm{m}$ and stained with periodic acid Schiff (PAS) and hematoxylin.

\footnotetext{
*This work was carried out under the fellowship program of the Japan Society for the Promotion of Science in 1987.
} 
For electron microscopy, two mice at each interval were perfused with phosphate buffered saline followed by $0.05 \mathrm{M}$ phosphate buffer- $5 \%$ formalin- $2 \%$ glutaraldehyde$1.5 \%$ sucrose through the left ventricle for $10 \mathrm{~min}$. The testis was removed and cut into small pieces, fixed with the above fixative for $2 \mathrm{hrs}$, post-fixed with $\mathrm{OsO}_{4}$ for $2 \mathrm{hrs}$, block-stained with $0.5 \%$ uranyl acetate overnight, dehydrated and then embedded in Epon. The ultrathin sections were stained with lead citrate.

\section{RESULTS}

Light microscopy: The effects of ligation of the efferent duct on the testis were not uniform at any interval. Hence, results from those mice that exhibited regressive changes in the seminiferous tubules are here reported. At 2-4 days post-ligation, regressive changes were seen only in the peripheral seminiferous tubules; the tubules contained few giant cells. By 6-8 days after ligation, giant cells were common in the majority of atrophic tubules (Fig. 1a). They appeared both in the epithelium and lumen of the tubules. The giant cells were round, measuring up to $40 \mu \mathrm{m}$ in diameter, and containing two to fifteen nuclei of the germ cells (Fig. 1). The commonest giant cells
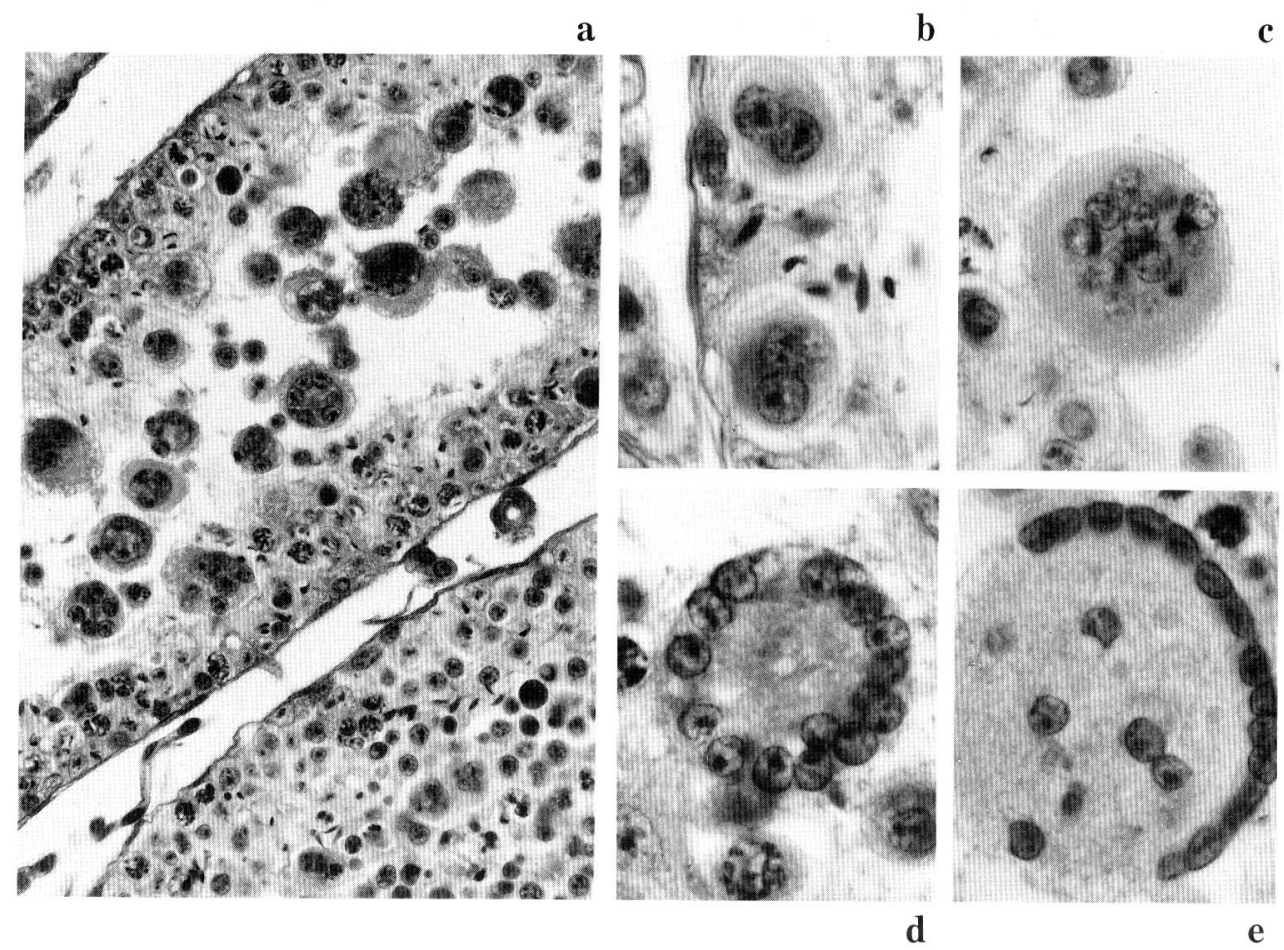

Fig. 1. Sections of the testis 8 days after efferent duct ligation. PAS-hematoxylin. a: $\times 300$, b-e: $\times 800$. a. Note the occurrence of many giant cells containing nuclei of germ cells in the seminiferous tubule. b. Giant cells with two nuclei. c. Giant cell with many scattered nuclei. d. Giant cell with many nuclei arranged along the periphery of the cell body. In this cell, PAS-positive acrosomes are oriented towards the periphery. e. Giant cell with many flattened nuclei arranged along the periphery of the cell body. 
were those with round nuclei of early spermatids, followed by those with flattened nuclei of late spermatids, while the least frequent were those with nuclei of spermatocytes. The giant cells formed of late spermatids possessed more nuclei than the others (Fig. 1e).

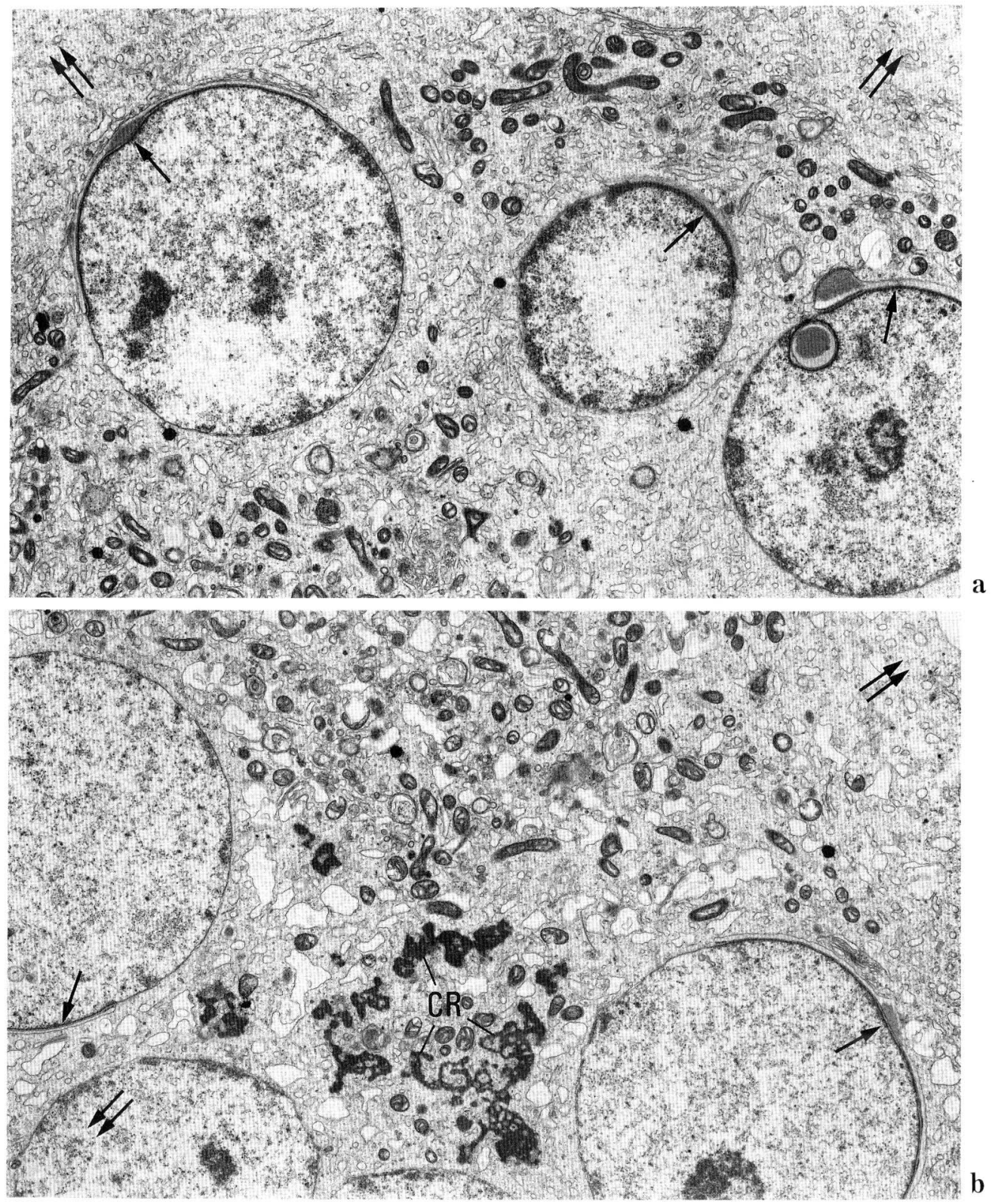

Fig. 2. a. and b. Spermatid giant cells in the testis 8 days after efferent duct ligation. Acrosomes (single arrows) of the nuclei in the giant cell are oriented towards the periphery (double arrows) of the cell body. The cytoplasm in the center of the giant cell shows an accumulation of cell organelles, heterogenous structures, and dense chromatoid bodies $(C R) . \times 6,000$ 
The smallest giant cell had two centrally placed nuclei which were attached to each other by a PAS-positive acrosome (Fig. 1b). The large cells possessed many peripheral nuclei and the PAS-positive acrosomes of these nuclei were usually oriented towards the rim of the cell body; the center of these cells showed PAS-positive

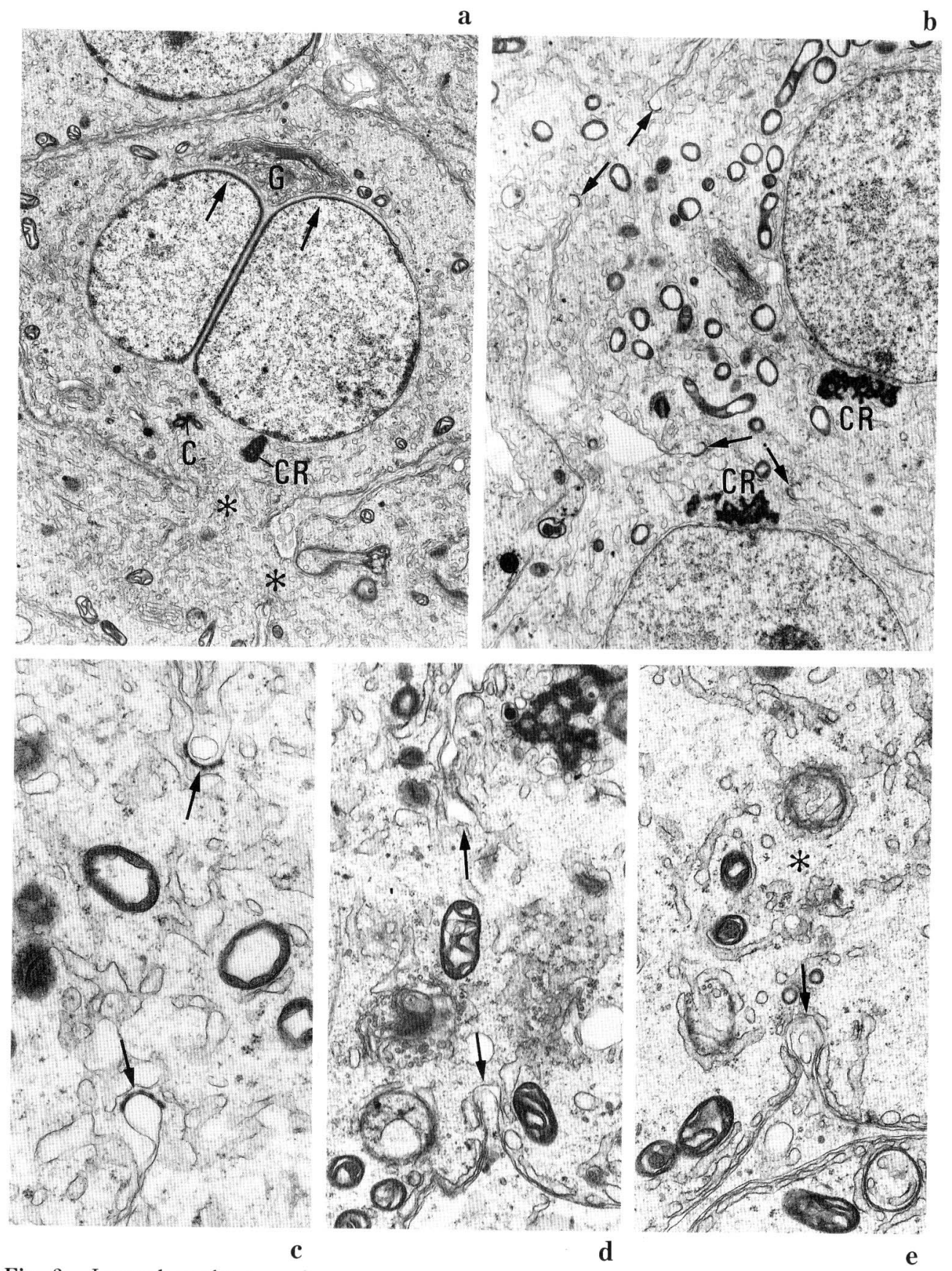

Fig. 3. Legend on the opposite page. 
cytoplasm (Fig. 1d, e). Flattened nuclei of late spermatids were arranged along the rim of the giant cells. Giant cells with many nuclei showing random orientation of acrosomes were rarely encountered. The nuclei of early spermatids lacking acrosomes were often scattered in the cytoplasm of the giant cells (Fig. 1c).

Electron microscopy: The present electron microscopic observations deal mainly with giant cells containing round nuclei of early spermatids, as these cells were frequently observed. In most of the multinucleated giant cells, acrosomes were oriented towards the periphery of the cell body and exhibited Golgi, cap, and acrosome phases (Fig. 2). Sometimes two or three nuclei were connected together with a common acrosome while the center of the acrosome still showed peripheral orientation. The cytoplasm in the center of the giant cells had an accumulation of many mitochondria, lamellated membranes, and heterogenous membrane-bound structures with various contents such as granules, fine vesicles, and myelin like figures; dense chromatoid bodies and centrioles were also found in this region (Fig. 2). The cytoplasm in the periphery as well as in the center contained vesicular endoplasmic reticulum.

When giant cells had two nuclei, a T-shaped acrosome was shared by both nuclei (Fig. 3a). The Golgi apparatus was found at the pole where the acrosome was exposed to the cytoplasm; chromatoid bodies and centrioles were seen at the pole opposite to that of the Golgi apparatus; mitochondria also accumulated in this region, or else were randomly distributed (Fig. 3a b). Giant cells with two to five nuclei occasionally showed intercellular bridges with adjacent spermatids (Fig. 3a).

The intercellular bridges connecting giant cells and uninucleated spermatids were usually wide and deformed as compared with the normal bridges which are narrow and exhibit a C-shaped or semicircular profile with membrane-bound dense material (Fig. 3). Intercellular bridges without any dense material underneath the plasma membrane were often observed (Fig. 3d, e). The bridges were noticed mostly on the side opposite to that of the developing acrosomes where the cytoplasmic area had mitochondria, endoplasmic reticulum, centrioles, and chromatoid bodies.

Uninucleated spermatids had normal intercellular bridges. The pole of the cell opposite to that of the acrosome was usually observed towards the bridge (Fig. $3 \mathrm{~b}$ ).

Some large giant cells showed dense cytoplasm containing many vacuoles and appeared degenerated. However, those cells with fewer nuclei showed less degeneration.

Fig. 3. Germ cells 8 days after efferent duct ligation. a. A giant cell with two nuclei is connected by an intercellular bridge with a neighbouring cell (asterisks indicate intercellular bridges). The two nuclei share a T-shaped acrosome (arrows). The Golgi apparatus $(G)$ is seen at the pole where the acrosome is exposed to the cytoplasm. $C$ centriole, $C R$ chromatoid body. $\times 5,000$. b. Uninucleated spermatids are connected by intercellular bridges. The intercellular bridges (arrows) showing a C-shaped membrane with dense material are seen towards the tail pole which contains chromatoid bodies $(C R) . \times 7,000$. c. Nearly normal intercellular bridge showing the membrane with dense material (arrows). $\times 18,000$. d. Disintegrated intercellular bridge exhibiting loss of membrane-bound dense material (arrows). $\times 18,000$. e. A part of a widened intercellular bridge (asterisk). The indented membrane (arrow) of the bridge shows no dense material. $\times 14,000$ 


\section{DISCUSSION}

Multinucleated giant cells as observed in the testes of efferent duct ligated mice in the present study have also been reported in animals and men under different experimental and pathological conditions (BENITZ and DAMBACH, 1965; HolsteIn, 1975; SinGH, 1982; HOLSTEIN and ECKMANN, 1986). They have been also described in mice following cryptorchidism (ABE and TAKANO, 1987) and treatment with 5-thio-D-glucose (SINGH, 1983), 1-(2, 4-dichlorobenzyl)-1H-indazole-3-carboxylic acid (SINGH and DominIC, 1984) and prostaglandin (SINGH and DomINIC, 1986). The occurrence of giant cells in the testis is considered to be an expression of germ cell degeneration. The genesis of these cells has been discussed in relation to the confluence of cell membranes of adjacent germ cells, alterations in the intercellular bridges of germ cells, and the abnormal division of germ cells (PLÖEN, 1973a, b; HOLSTEIN, 1975; TORGERSEN et al., 1982; HOLSTEIN and ECKMANN, 1986). This study deals mainly with the changes in the intercellular bridges.

DYM and FAWCETT (1971) reported that the intercellular bridges that connect the groups of germ cells in the seminiferous tubules are narrow and have membrane-bound dense material. By contrast, in the ligated mice this bridge often appeared wide with no dense material. Our observations, therefore, suggest that the fusion of germ cells resulting in the formation of giant cells occurs primarily due to the opening and ensuing damage to the intercellular bridges. Electron microscopic studies on the testis after cryptorchidism (PLÖEN, 1973a, b) and treatment with bacterium Calmette-Guerin (BCG) (TORGERSEN et al., 1982) also suggest that the intercellular bridge is susceptible to various experimental manipulations. In the present study, it is probable that the increase in the intratubular pressure in the testis after ligation of the efferent duct caused damage to the bridge resulting in the fusion of the germ cells. It is assumed that the membrane-bound dense material is essential for the normal maintenance of the bridge, and is sensitive to various injuries.

Small giant cells develop into larger cells by the fusion of more and more spermatids. This contention is supported by the observation that giant cells with two to five nuclei were seen connected by intercellular bridges with adjacent spermatids in the early phase of development. The nuclei in the giant cells exhibited further phases of development of acrosome before finally degenerating.

In giant cells, the acrosomes and nuclei were usually oriented towards the periphery of the cell, while the mitochondria, centrioles, and chromatoid bodies that form the tails of sperm were accumulated in the central region in the cytoplasm. This orientation of the cellular elements in the giant cells is related to the polarity of spermatids: spermatids exhibit a polarity with regard to the development of the acrosome and tail in normal spermiogenesis (FAWCETT et al., 1971). The intercellular bridge was seen near the pole of spermatids where the tail of spermatozoa develops. The fusion of spermatids resulting from damage to this bridge may lead to the orientation of the organelles of the tail formation towards the center and the acrosome towards the periphery in the giant cells. The results also suggest that when small giant cells with two or three nuclei of early spermatids in a Golgi or cap phase grow into larger cells with many nuclei in further phases of acrosome development, the organelles for the formation of the tail move apart from the acrosomes and accumulate in the center of the giant cells. Relevant to the present observation is the case during normal spermiogenesis (FAWCETT et al., 1971). However, spermatids in the giant cells did not show any development of the tail, and finally degenerated. 


\section{REFERENCES}

Abe, K. and H. Takano: Response of the mouse epididymal duct to the disappearance and reappearance of spermatozoa induced by temporal cryptorchidism. Arch. histol. jap. 50: 315-324 (1987).

Benitz, K.-F. and G. Dambach: The toxicological significance of multinucleated giant cells in dystrophic testes of laboratory mammals and man. Arnzeim. Forsch. 15: 391-404 (1965).

Dym, M. and D. W. Fawcett: Further observations on the numbers of spermatogonia, spermatocytes, and spermatids connected by intercellular bridges in the mammalian testis. Biol. Reprod. 4: 195-215 (1971).

Fawcett, D. W., W. A. Anderson and D. M. Philips: Morphogenetic factors influencing the shape of the sperm head. Devel. Biol. 26: 220-251 (1971).

Holstein, A. F.: Morphologische Studien an abnormen Spermatiden und Spermatozoen des Menschen. Virchows Arch. A pathol. Anat. Histol. 367: 93-112 (1975).

Holstein. A F. and C. Eckmann: Multinucleated spermatocytes and spermatids in human seminiferous tubules. Andrologia 18: 5-16 (1986).

Plöen, L.: An electron microscope study of the delayed effects on rabbit spermateleosis following experimental cryptorchidism for twenty-four hours. Virchows Arch. Abt. B Zellpathol. 14: 159-184 (1973a).

: A light microscope study of the immediate and delayed effects on rabbit spermatogenesis following experimental cryptorchidism for twenty-four hours. Virchows Arch. Abt. B Zellpathol. 14: 185-196 (1973b).

Singh, S. K.: Giant cells in the testis of the musk shrew, Suncus murinus L. following vasectomy and treatment with certain antispermatogenic drugs. Sci. Culture 48: 179180 (1982).

: Effect of 5-thio-D-glucose on the testis, epididymis and accessory sex glands of the laboratory mouse. Indian J. Zool. 11: 19-25 (1983).

Singh, S. K. and C. J. Dominic: Effect of 1-(2, 4-dichlorobenzyl)-1H-indazole-3-carboxylic acid (DICA) on the sex organs of the male laboratory mouse. Exp. clin. Endocrinol. 83: 291-296 (1984).

- Prostaglandin $\mathrm{F}_{2} \alpha$-induced changes in the sex organs of the male laboratory mouse. Exp. clin. Endocrinol. 88: 309-315 (1986).

Torgersen, M. H., E. Rovan, M. Steiner, J. Frick and H. Adam: BCG-induced orchitis: structural changes during the degeneration of seminiferous tubules of rats and rabbits. Urol. Res. 10: 97-104 (1982).

阿部和 厚

干 060 札幌市北区北 15 条西 7 丁目

北海道大学医学部

解剖学第三講座
Prof. Kazuhiro ABE

Department of Anatomy

Hokkaido University School of Medicine

Kita 15, Nishi 7, Kita-ku

Sapporo, 060 Japan 